\title{
Sturge Weber Syndrome with Paroxysmal Hemiparesis
}

\author{
Amit Chaurasiya ${ }^{1}$, Rahul Sharma ${ }^{2}$, Gunjan Kela ${ }^{3}$, Sharad Thora ${ }^{4}$, Ankita Maheshwari ${ }^{5}$
}

\begin{abstract}
${ }^{1}$ Department of Paediatrics, Sri Aurobindo Medical College and PG Institute, Indore, Madhya Pradesh, India. ${ }^{2}$ Department of Paediatrics, Sri Aurobindo Medical College and PG Institute, Indore, Madhya Pradesh, India. ${ }^{3}$ Department of Paediatrics, Sri Aurobindo Medical College and PG Institute, Indore, Madhya Pradesh, India. ${ }^{4}$ Department of Paediatrics, Sri Aurobindo Medical College and PG Institute, Indore, Madhya Pradesh, India. ${ }^{5}$ Department of Paediatrics, Sri Aurobindo Medical College and PG Institute, Indore, Madhya Pradesh, India.
\end{abstract}

\section{INTRODUCTION}

Sturge-Weber Syndrome (SWS) is a multisystem disorder involving the neurological system, skin and eyes (phakomatosis). It occurs in 1 in 50,000 to 1 in 60,000 births.(1) Sturge-Weber syndrome (SWS) is a disorder of the neurocutaneous system present since birth, typically categorized by leptomeninges angiomas of telangiectatic veins, and one sided angiomatous nevus of the face and involving the first branch at least of the trigeminal nerve sensory distribution. Insufficiency of normal superficial cortical veins if seen many times on pathological examination.(2) Hypoperfusion and impairment of neuronal metabolism can occur due to cerebral damage as a result of inefficient flow of venous blood.(3)

SWS is referred to as 'complete' when both CNS and facial angiomas are present and 'incomplete' when only the face or CNS is affected.(1) Clinical features in children include focal or generalized seizures, variable degree of learning disability and neurologic deficits such as hemiplegia and homonymous hemianopia.(4) More often than not, epilepsy is a presenting symptom of SWS with onset during childhood.(5) Seizures usually begin in infancy with profound seizure activity with resultant further neurologic and developmental deterioration seen in few cases. Early diagnosis is likely to be associated with a better outcome.(4) Epilepsy can cause transient neurological deficits in patients with SWS due to temporary ischemia of cortex in view of underlying vascular malformation.(2) We are reporting a case of four-year-old female child diagnosed as Sturge-Weber syndrome who came with second episode of hemiparesis.

\section{PRESENTATION OF CASE}

The patient was full term, vaginally delivered female child at hospital with birth weight of $2.5 \mathrm{Kg}$ without any antenatal, perinatal and postnatal complications till six months of age. The child was neurologically normal with milestones achieved for age. At six months of age there was history of fall from bed associated with left sided focal seizures and left sided hemiplegia noticed after fall. Investigations done at that time were suggestive of normal neuroimaging and EEG. No documents of the same were available.

The child was on compliant antiepileptic therapy since then and was seizure free for about 15-20 days back before second admission at three years nine month of age. The anti-epileptic drugs were decreased without paediatric consultation following which there were 3-4 episodes of left sided seizure with interictal normal sensorium. The hemiplegia which occurred at six months of age had improved to such an extent that child was able to walk and run few steps. Mentally she was normal for age but after second episode of seizure again she developed left sided hemiparesis. This time the weakness improved over 7-10 days so it was concluded to be transient ischaemic attacks based on clinical course and investigations.
Corresponding Author:

Dr. Amit Chaurasiya,

\#107, Harshringar Hostel,

SAIMS Campus, Bhawrasla,

Indore, Madhya Pradesh, India.

E-mail:

dr.amitkumarchaurasiya@gmail.com

DOI: $10.14260 / j e m d s / 2019 / 710$

Financial or Other Competing Interests: None.

How to Cite This Article:

Chaurasiya A, Sharma R, Kela $G$, et al. Sturge weber syndrome with paroxysmal hemiparesis. J. Evolution Med. Dent. Sci. 2019;8(43):3276-3278, DOI: $10.14260 /$ jemds $/ 2019 / 710$

Submission 31-07-2019,

Peer Review 08-10-2019,

Acceptance 15-10-2019,

Published 28-10-2019. 

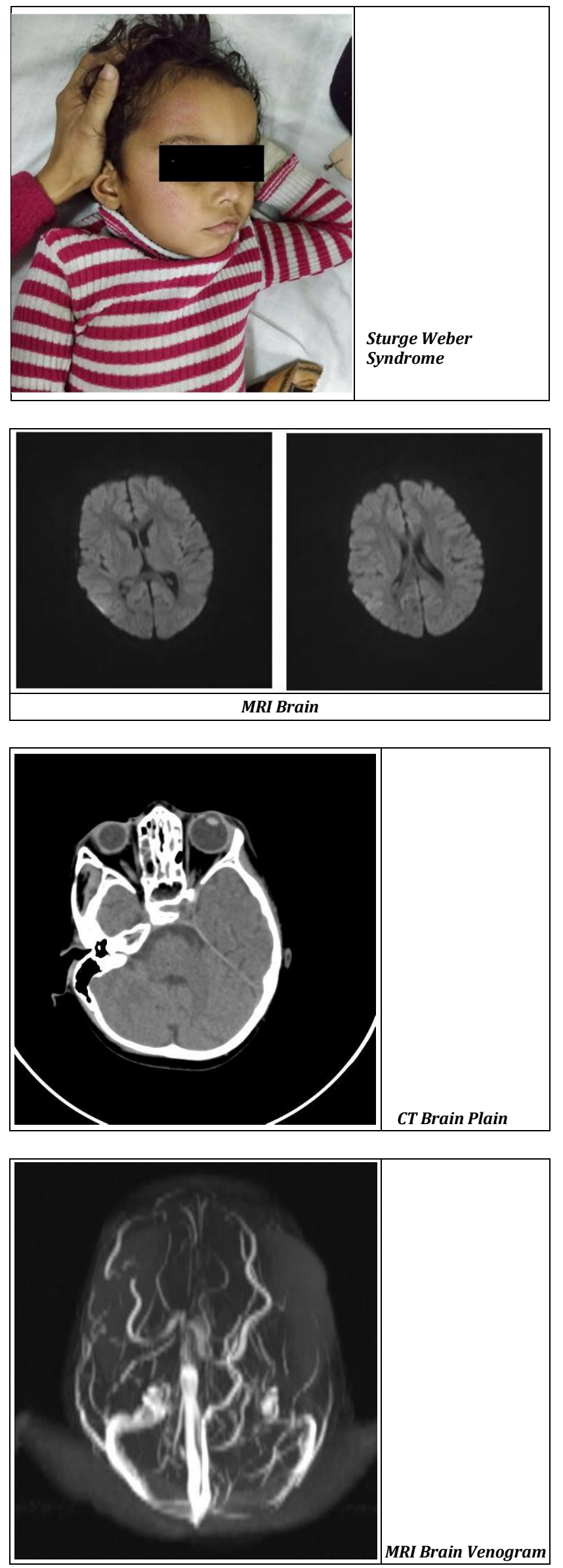

No significant stenosis or abnormal dilatation seen in circle of Willis angiogram. MRI brain study reveals small area of gliotic scarring in the right high parietal lobe parenchyma. Mild to moderate inflammatory mucosal thickening is seen in the both ethmoid and maxillary sinuses. CT study reveals irregular areas of gyriform calcification with gliosis in right fronto-parieto-occipital cortex. These findings were suggestive of Sturge-Weber syndrome.

CT + MRI brain study reveals irregular areas of gyriform calcification with gliosis in right fronto-parieto-occipital cortex. These findings have been described in Sturge-Weber syndrome. Few prominent cortical veins are seen in the region of right fronto-parieto-occipital cortex. The superior sagittal, straight, bilateral transverse, sigmoid sinuses and proximal internal jugular vein reveal normal flow without any thrombosis. Hypoplastic left transverse sinus seen. There is no evidence of venous sinus thrombosis. EEG and 2D-Echo were normal. Routine haematological investigation and coagulation profile were normal. The child was discharged on aspirin prophylaxis and carbamazepine and physiotherapy.

\section{DISCUSSION}

There is finite usage of diffusion weighted MRI to differentiate between ischaemia or epileptic causes of hemiparesis and epilepsy;(6) however, it can be used for investigation of those with acute cerebral ischaemia(7) and it is also useful for patients diagnosed with status epilepticus.

2-deoxy-2 [18F] fluoro-D-glucose positron emission tomography (FDG PET) is helpful in determining the intensity and severity of glucose asymmetry for severity of seizures and decline of cognitive function in SWS(8) Patients with SWS who had seizures showed cerebral blood flow in lower cortex region on single photon emission computed tomography. Due to enormous logistical obstacles of ictal scanning FDG PET and SPECT scanning are not being used to comprehend the difference between epilepsy and ischaemia in individuals with SWS.

Inferences have been made in the past about the value of aspirin in patients with SWS and transient focal deficits. One of the past studies involving 14 patients have shown a $65 \%$ decrease of stroke like events after using aspirin.(3) Hence it was suggested that aspirin therapy should be taken into consideration in patients with signs of paroxysmal hemiparesis with no ictal epileptiform activity on EEG.

A case series from the UK with 5 children with SWS (4/5 children were already on aspirin) reported transient onset/deteriorating of hemiplegia after minor head traumas between age group of 10 months and 1 years, which gradually resolved after a certain time period.(4)

First episode of seizure associated with recurring seizures and transient neurological deficit can trigger permanent hemiplegia. There are documented cases of permanent hemiplegia in relation to recurrent episodes of hemiconvulsions and migrainous headaches. $(1,4,9,10)$ Appropriate seizure control along with positive changes in focal deficit or at least prevention of seizures in SWS is suggested.(4) Stringent seizure control in children diagnosed with SWS is helpful for a better neurological outcome. 


\section{REFERENCES}

[1] Takeoka M, Riviello JJ Jr. Sturge-Weber syndrome. Medscape,

2015.

http://emedicine.medscape.com/article/1177523

(Accessed on 5th September, 2015).

[2] Gomez MR, Bebin EM. Sturge-Weber syndrome. In: Gomez MR, Bebin EM, eds. Neurocutaneous diseases: a practical approach. Boston: Butterworths Publishers 1987.

[3] Maria BL, Neufeld JA, Rosainz LC, et al. Central nervous system structure and function in Sturge-Weber syndrome: evidence of neurologic and radiologic progression. J Child Neurol 1998;13(12):606-18.

[4] Zolkipli Z, Aylett S, Rankin PM, et al. Transient exacerbation of hemiplegia following minor head trauma in Sturge-Weber syndrome. Dev Med Child Neurol 2007;49(9):697-9.
[5] Garcia JC, Roach ES, McLean WT. Recurrent thrombotic deterioration in the Sturge-Weber syndrome. Child's Brain 1981;8(6):427-33.

[6] Lansberg MG, O'Brien MW, Norbash AM, et al. MRI abnormalities associated with partial status epilepticus. Neurology 1999;52(5):1021-7.

[7] Roberts TP, Rowley HA. Diffusion weighted magnetic resonance imaging in stroke. Eur J Radiol 2003;45(3):185-94.

[8] Lee JS, Asano E, Muzik O, et al. Sturge-Weber syndrome: correlation between clinical course and FDG PET findings. Neurology 2001;57(2):189-95.

[9] Dora B, Balkan S. Sporadic hemiplegic migraine and SturgeWeber syndrome. Headache 2001;41(2):209-10.

[10] Iizuka T, Sakai F, Yamakawa K, et al. Vasogenic leakage and the mechanism of migraine with prolonged aura in Sturge-Weber syndrome. Cephalalgia 2004;24(9):76770. 